\title{
Improving Municipal Solid Waste Land Filling Disposal Process: Experiments with a Laboratory Scale Rotary Kiln
}

\section{Jean Fidèle Nzihou}

Ecole Normale Superieure, Université de Koudougou, Koudougou, Burkina Faso.

Email: jean_fidele@hotmail.com

Received December $26^{\text {th }}, 2012$; revised February $8^{\text {th }}$, 2013; accepted February $16^{\text {th }}, 2013$

Copyright (c) 2013 Jean Fidèle Nzihou. This is an open access article distributed under the Creative Commons Attribution License, which permits unrestricted use, distribution, and reproduction in any medium, provided the original work is properly cited.

\begin{abstract}
Developing countries often face the challenge of managing continuously growing quantity of municipal waste. Waste is often disposed of by stockpiling and land filling because these have been found the cheapest waste disposal methods in the world. Unfortunately, these waste disposal methods are often source of visual pollution, water contamination and greenhouse effect gas emissions. Waste disposal by incineration has been found effective and now is one of the mostly used waste disposal method in several developed countries. Nevertheless, setting up appropriate waste incinerator requires a good of the combustion process. Unfortunately, direct studies on industrial facilities are not easily feasible because of technical issues and financial limitations. Studies and throughout testing frequently need to be carried out at laboratory scale. Work herein reported first overviewed operation conditions of the landfill facility in the town of Ouagadougou. In the second time for incineration simulation, batch experiments are carried out with a rotary kiln furnace to study the effects of the residence time on emissions of $\mathrm{NO}, \mathrm{NO}_{2}, \mathrm{CO}, \mathrm{CO}_{2}$ and $\mathrm{SO}_{2}$ in the atmosphere. For each rotation speed, emissions of $\mathrm{NO}, \mathrm{NO}_{2}, \mathrm{CO}, \mathrm{CO}_{2}$ and $\mathrm{SO}_{2}$ from the incineration of a household combustible fraction model waste consisting of wood (53\%), cardboard (25\%) and plastics (22\%) have been recorded. The lifespan of the land filling facility with incineration has been estimated. Our work show that it may be improved up to roughly three times that of simple land filling. Visual pollution maybe drastically reduced and atmospheric pollution reduced.
\end{abstract}

Keywords: Land Filling; Greenhouse Gases; Pollutants; Rotary Kiln; Lifespan

\section{Introduction}

In several sub-Saharan countries, governments and urban managers are often challenged by the management of continuously growing quantity of municipal and industrial wastes. In those countries, wastes are often disposed of by stockpiling and land filling. Ouagadougou, the biggest city of Burkina Faso for example only got its first land filling facility on February 05, 2005. In year 2011, 300,000 tons of municipal waste were produced in the Burkina Faso's political capital, 243,000 tons were collected and processed, of which $6 \%$ was recycled in compost or pellets [1]. This means that more than $90 \%$ of municipal waste is stockpiled. The same is true in several sub-Saharan countries.

As a result, the town of Ouagadougou's first and single modern stockpiling facility will only last for 20 years. The lifespan of this facility seems short, because if used, a waste incineration facility help reduce the volume of waste up to $90 \%$ and thus augment the lifespan of a stockpiling facility for the same built capacity.
In addition, the landfill site of Ouagadougou, the waste is exposed to air. This results in obvious visual pollution and odor pollution of surrounding areas. It is established that the landfill sites are sources of gas production resulting from chemical reactions and microbes acting upon the waste as the putrescible materials begins to break down [2]. Due to the constant production of landfill gas, the increase in pressure within the landfill (under the wastes) causes the gas's release into the atmosphere. Such emissions lead to important environmental, hygiene and security problems in the landfill $[3,4]$. According to [5], landfill gases have an influence on climate change. The major components are $\mathrm{CO}_{2}$ and methane, both of which are greenhouse gas. Methane is considered over 20 times more detrimental to the atmosphere than Carbon Dioxide.

It then appears that the present level of landfill disposal for municipal solid waste (MSW) and other organic combustible waste in developing countries, including Burkina Faso in general and the town of Ouagadougou in 
particular is not a sustainable option.

In fact, now days several countries enacts legislations rules for waste disposal that tend to ban stockpiling and restrict the use of land filling to inert waste. In several developed countries, incineration has become one of the two most used waste disposal method [6]. For example since June 1, 2005, untreated waste is no longer land filled in Germany [7], the same apply to England as of October 30, 2007 [8]. Waste incineration thus appears as an interesting alternative to the traditional disposal methods and can no longer be overlooked in several circumstances.

Numerous technologies have been developed for waste incineration, which is burning solid waste in presence of oxygen. The most used are gate type combustion kiln and rotary kilns. Rotary kiln are popular for this purpose because of their flexibility and the capability of accepting raw material of various composition and shape. Nevertheless, incineration can be source of pollution if it is not correctly carried out. Therefore a good knowledge of incineration facilities is a prerequisite before any waste incineration facility installation. Unfortunately, direct studies on industrial facilities are not only too costly, but also difficult to carry out. This is why fundamental researches are merely carried out on laboratory scale equipments.

The Laboratory of Environmental Physics and Chemistry has acquired a laboratory scale rotary kiln for purpose of studying municipal incineration since year 2003. Although rotary kilns are among the most well-established units operation in the process industry, they are among the least understood [9]. In fact, rotary kilns performances and pollutants releases depend on a great number of parameters. Apart from physical parameters of the kiln, materials feed also affect the kiln efficiency and pollutants releases.

As reported in [10], short-term testing for NOx will not provide a statistically meaningful estimate to be made of the monthly or yearly mass emissions of NOx from a facility. To develop a meaningful estimate of NOx emissions from a cement kiln for example with a statistical measure of confidence, a continuous emissions monitor (CEM) must be used, and data must be collected for several months, or longer if multiple fuels are used. Once data are collected, they must be subjected to rigorous statistical analyses to establish the mean and the variability of the emissions. Without such analyses, NOx emissions data are of little to no value in establishing emission factors or limits.

NOx emissions rates are also site and kiln-specific. NOx emissions from two apparently similar kilns may not be similar. The causes are not fully understood; however, one cause may be due to the raw materials [11]. This clearly indicates that a thorough testing of our labo- ratory scale rotary kiln is required in order to get the best of it and avoid pollution transfer during laboratory experiments. Under this scope we will focus on the effects of the residence time on the temperatures inside a laboratory scale rotary kiln and the emissions of NO, CO, $\mathrm{CO}_{2}$ and $\mathrm{SO}_{2}$. For each rotation speed, temperatures and emissions of $\mathrm{NO}, \mathrm{CO}, \mathrm{CO}_{2}$ and $\mathrm{SO}_{2}$ will be recorded. This will enable us to see how these emission varies when the rotation speed vary, in order to lower these emissions and help protect the environment.

In order to insure the repeatability of our experiments and to avoid complications that may arise from the use of a real waste of which composition is very complex and the heterogeneity very high, we will use a "model waste". That is a waste made from the model drawn from the characterizations of household wastes conducted in the town of Ouagadougou, Burkina Faso.

\section{Materials and Method}

\subsection{The Rotary Kiln}

It consist of a cylinder slightly inclined (17), to which is appended the primary burner noted burner 1 (RG1). This cylinder have a diameter of $88 \mathrm{~cm}$, measure $108 \mathrm{~cm}$ in length, is suspended on bearings ball which allow its rotation around its axis of symmetry as depicted in Figure 1. From inside to the outside, a vertical cut shows:

- The refractory: of a $4 \mathrm{~cm}$ thickness, it has to tolerate the high temperatures found in the furnace. Being in direct contact with hot gases in its higher part and in contact with the solid bed in its lower part; the refractory material undergoes important temperature variations. It must thus be able to support important thermal shocks;

- The heat insulator: it is used to limit the losses of heat and aim to maintain the temperature of the furnace around some average values;

- The sheet steel: it confers a good mechanical rigidity to the unit.

On the left door of the cylinder is fixed the primary burner (RG1) made by Riello GULLIVER. Its characteristics according to [12] are:

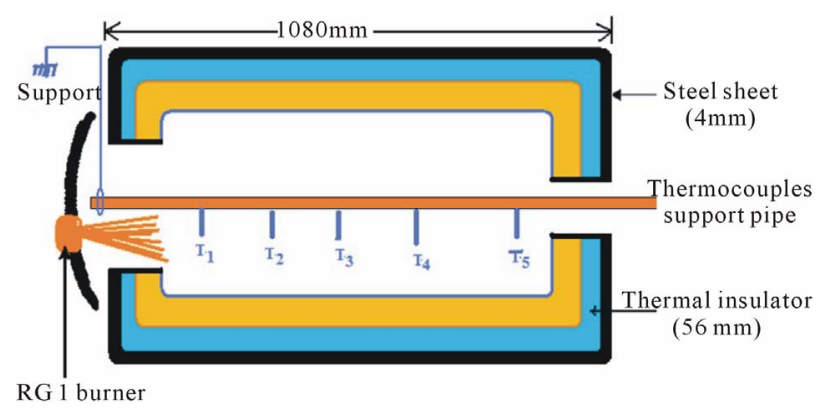

Figure 1. Vertical cut of the primary combustion chamber with thermocouples locations. 
- Fuel maximum viscosity of $6 \mathrm{~mm}^{2} / \mathrm{s}$ at ambient temperature $\left(20^{\circ} \mathrm{C}\right)$;

- Single-phase power supply, $50 \mathrm{~Hz}, 230 \mathrm{~V} \pm 10 \%$;

- Electric motor of 170 W/0.85 A and 2750 rpm;

- Flame control by photo resistive cell (in the event of a problem, the burner is automatically stopped);

- Minimum/maximum power output: 21 kw/60 kw;

- Minimal/maximal mass throughput of the fuel: 1.8 $\mathrm{kg} / \mathrm{h}$ and $5 \mathrm{~kg} / \mathrm{h}$;

- Fuel pump pressure: 8 to 15 bar.

The primary burner air intake is located at the bottom of the burner; it is controlled by the burner engine. The secondary air can be injected with a shutter available on the primary combustion chamber door. The primary combustion chamber excess of air is adjustable using an index accessible from the outside of the burner.

The operation power is determined by the mass throughput of the burner, itself determined by the nozzle used. In accordance with the directive output 92/42/CEE, it is necessary to determine the jet, the pressure of the pump of the fuel, the flow of the burner, the adjustment of the head of combustion and the adjustment of the primary combustion chamber air shutter as described in reference [12].We used a GPH 1.00 nozzle, the fuel flow of the primary combustion chamber burner is thus of (4 \pm $0.16) \mathrm{kg} / \mathrm{h}$. The combustion head must thus be at index 4 , the adjustment of the shutter of air to index 5.6; with theses settings, the thermal power produced by the primary combustion chamber burner is $48.6 \mathrm{~kW}$.

Five type $\mathrm{K}$ thermocouples have been placed inside the combustion chamber. These are supported by a pipe running from the primary burner (RG1) to the postcombustion chamber at the right side.

\subsection{The Pollutants Measuring Unit}

Pollutants gases are measured with a Testo ${ }^{\mathrm{TM}} 350$ which can measure:

- The volume percentage of the oxygen in the combustion gases (0 to $21 \%$ );

- The concentration in part per million (ppm) of NOx, $\mathrm{CO}$ and $\mathrm{SO}_{2}$;

- $\mathrm{CO}_{2}$ proportion (\%) is calculated from the $\mathrm{O}_{2}$ and $\mathrm{CO}$ concentration;

- etc.

Pollutants concentrations given by the Testo ${ }^{\mathrm{TM}} 350$ are calibrated to an $8 \%$ oxygen concentration. Data coming from the Testo ${ }^{\mathrm{TM}} 350$ go to the serial port of the PC.

There are five thermocouples inside the primary combustion chamber (Figure 1). All these thermocouples are connected to a centralization box "Clear Signal ${ }^{\circledR} \mathrm{MX}$ 2000" with a compensation cable. From the centralization box, there is a S-1800 cable that go to DAS-TC/B card. The DAS-TC/B is an analog-digital acquisition card plugged into the computer on an ISA slot. Data coming from the gases combustion and temperatures from thermocouples are handled with the Tespoint ${ }^{\mathrm{TM}}$ software.

\subsection{The Model Waste}

\subsubsection{Why a Model Waste?}

Due to the heterogeneity of wastes, direct studies on industrial facilities are not only too costly, but also difficult to carry out. These experiments need to be reproducible. This is almost impossible to achieve with real waste due to its heterogeneity. Waste characterisations methods aim to identify the main components of waste and it's essentials properties. These methods based on statistical techniques shows that highly heterogeneous wastes consist of main components of cellulose's type and plastics. These mains and dominants components control the waste properties. It is then possible to draw a model waste from the real waste that will have the same properties. This enables one to reproduce experimental conditions for researches purposes.

\subsubsection{The Waste Model Drawing}

From the results of waste characterisations, one can then draw a model waste that enable laboratory scales studies, namely combustions test. In this part of our work, we will first give the waste model of the town of Ouagadougou. It is drawn from waste characterizations carried out in the town of Ouagadougou in dry season by [13] and wet seasons by [14]. These two characterizations were chosen in order to cover an entire year of characterization campaign. With the assumptions made by [14], we draw Table 1 below.

From Table 1, we see that there are only $4.18 \%$ of metals in the town of Ouagadougou's household waste. This owe to the fact that in this low level income country,

Table 1. Town of Ouagadougou's waste composition and assimilation to dominants components.

\begin{tabular}{ccccc}
\hline \multirow{2}{*}{ Components } & \multicolumn{4}{c}{ Assimilation to ... } \\
\cline { 2 - 5 } & Wood & Paper & Plastics & Total \\
\hline Fermentable & 39.50 & - & - & 39.50 \\
Papers & - & 8.56 & - & 8.56 \\
Textiles & - & 5.82 & - & 5.82 \\
Plastics & - & - & 9.56 & 9.56 \\
Metals & - & - & - & 4.18 \\
Glass & - & - & - & 2.73 \\
Specials & - & - & 1.59 & 1.59 \\
Unclassed composites & - & 2.27 & 2.27 & 4.54 \\
Unclassed unburnables & - & - & - & 18.49 \\
Composites & - & 2.01 & 2.01 & 4.02 \\
Total & 39.5 & 18.86 & 15.43 & 100 \\
\hline
\end{tabular}


peoples do recycle metals from trash. There is almost nothing significant remaining as metals at the land filling facility, as metals have economic value in this country and is picked out at the upstream for recycling or reuse. Glass also only represents $2.73 \%$ of the waste for same reasons. Economical context therefore avoid us to deals with high quantities of metals and glass in household waste.

Environmental regulations become stricter and require a deep control of atmospherics pollutants releases. Therefore a waste incineration facility must reduce its pollutants releases to a minimum. It must then:

- Avoid burning metals that will otherwise be found in flying ash (this is in our favour);

- Avoid burning products that produce highly toxics volatiles such as sulphur and chlorine;

- Optimise the combustions parameters. This requires a good knowledge of the physicals and chemicals properties of the waste to be burned;

- Operate in economically feasible conditions.

These requirements bring us to draw a model waste in which:

- Metals will not burned: they should be picked out at the incinerator upstream and recycled;

- Only combustibles components should be burned because incombustibles materials such as rubble reduce the combustion efficiency, and thus the economic efficiency of the incineration facility, non combustible should be directly sent to landfill or recycled;

- Waste combustion will be simulated in laboratory on representative samples.

The waste model we have drawn is restricted to the combustible part of the municipal waste of the town of Ouagadougou. Several chemicals analysis had shown that complexes components as the fermentable and papers had similar properties as simpler components such as wood and cardboard $[15,16]$. This led us to assimilate fermentable components to wood. Papers and cardboards are made from vegetal fibbers. Cardboard is obtained by paper agglomeration and it has a similar chemical composition as papers. We then assimilated papers to cardboard. Municipal waste characterisations in France had showed that plastics materials are made with $91 \%$ of poly ethylene (P.E.T.) and 9\% of polyamide 6 - 6 [17]. Specials consist of plastics films and their polymers. They are assimilated to plastics. With the others assumptions were made by [14], let us consider the weight of each component in the total burnable material waste. We obtain Table 2.

The composition of this model waste is $53.5 \%$ of wood, $25.5 \%$ of cardboard, $19 \%$ of P.E.T and $2 \%$ of polyamide 6 - 6. In practice, P.E.T and polyamide 6 - 6 are designated und the name plastic with total percentage
Table 2. Proportions of components in the model waste.

\begin{tabular}{cccccc}
\hline & Wood & $\begin{array}{c}\text { Card } \\
\text { board }\end{array}$ & P.E.T. & $\begin{array}{c}\text { Polyamid } \\
6-6\end{array}$ & Total \\
\hline Weight & 39.5 & 18.86 & 14.02 & 1.41 & 73.79 \\
Proportion & 53.53 & 25.56 & 18.99 & 1.91 & 99.99 \\
Percentage & $53.5 \%$ & $25.5 \%$ & $19 \%$ & $2 \%$ & $100.0 \%$ \\
\hline
\end{tabular}

of $19+2=21 \%$. Thus the composition of the used fuel: Wood: 54\%, cardboard: 25\% and plastic: 21\%. Further calculations were done by [18] and led to the following elemental formula for this household waste model:

$\mathrm{C}_{4.24} \mathrm{H}_{6.16} \mathrm{O}_{2.69} \mathrm{~N}_{0.01} \mathrm{~S}_{0.005}$.

\subsection{Estimation of the Land Filling Facility Lifespan}

Let us considers that the land filling facility may receive up to $Q$ quantity (or volume) of waste and does annually receive a quantity $A_{0}$ of untreated and not recycled municipal waste. The land filling lifespan $d_{0}$ could roughly expressed as follow:

$$
d_{0}=\frac{Q}{A_{0}}
$$

If waste is incinerated before land filling, this should only apply to the combustible fraction $A_{c}$. There is also a quantity $A_{r}$ of waste that will be recycled and a quantity $A_{u}$ consists of unburnable materials such as rubble and sweepings should not undergo incineration and will directly go to land filling.

The annual quantity of collected waste for land filling is then given by Equation (2) below:

$$
A_{0}=A_{r}+A_{u}+A_{c}
$$

Recycled waste should no longer be accounted:

$$
A=A_{u}+A_{c}
$$

Quantities in second hand of Equations (3) may be expressed as follow:

$$
\begin{aligned}
& A_{u}=\alpha A_{0} \\
& A_{c}=\beta A_{0}
\end{aligned}
$$

With: $\alpha$ and $\beta$ respectively unburnable and combustible fractions of the municipal waste.

Reporting Equations (4) and (5) in Equation (3) and then in Equation (1) gives:

$$
d_{0}=\frac{Q}{A_{0}(\alpha+\beta)}
$$

With a volume reduction rate of more than $90 \%$, there will only remain less than $10 \%$ of $A_{c}$ to put in land. Equation (5) may be rewritten as follow:

$$
A_{c}=\varepsilon A_{0}
$$


The new landfill duration is then:

$$
d=\frac{Q}{A_{0}(\alpha+\varepsilon)}
$$

From Equations (6) and (8), we deduce:

$$
d=d_{0} \frac{\alpha+\beta}{\alpha+\varepsilon}
$$

\subsection{Experimental Procedure}

Because a kiln operation depend on several parameters, we have made whatever was possible to keep all other operation parameters as constants as feasible. Excess air, primary burner fuel input, kiln slope, mass feed, waste feed granularity are all supposed constants. As waste moisture content highly affect the combustion process [19], all burned waste was first dried several days under sunlight until all waste components appear totally dry. Although the better would be drying in a steamer, ours was out of service at the time of experiments. Nevertheless, we think that moisture content is less than $15 \%$ because in the town of Ouagadougou, temperature under sunlight even attains $40^{\circ} \mathrm{C}$ in dry season. below:

All experiments are carried out following the protocol

- Measurement of the weight of waste;

- Cleaning of the combustion chamber from any previous combustion refuse materials;

- Kiln preheating in order to have a temperature about $150^{\circ} \mathrm{C}$. If the experiment follow another, this condition is meet if the kiln is kept closed after the previous combustion no more than 10 minutes,

- Introduction of the model waste into the kiln, closing the door;

- Testo $^{\text {TM }} 350$ start, checking and set-up;

- Start of the data acquisition software (Testpoint ${ }^{\mathrm{TM}}$ ) on the PC;

- Kiln rotation switch turned "ON" and lightening of the waste;

The combustion process will be considered as finished and the acquisition stopped when all the following three conditions are meet: residual $\mathrm{O}_{2}$ concentration switch back to more than $19.5 \%, \mathrm{CO}_{2}$ concentration is less than $1.5 \%$, the post combustion chamber exit temperature $\left(\mathrm{T}_{5}\right)$ is less than $150^{\circ} \mathrm{C}$.

\section{Results and Discussions}

\subsection{Use of the Waste Model}

In all this work, the burned materials consist of the model waste made with $54 \%$ of wood. We used the wood found with local furniture makers. Cardboard contribute to $24 \%$ of the weight. It is made with small $2 \mathrm{~cm}$ by $2 \mathrm{~cm}$ about parts cute from packing cardboard. Plastics in the pro- portion of $22 \%$ consists of mineral water bottles to which we withdrawn caps, printed labels and glue.

\subsection{Rotation Speed Calibration}

Residence time depend on the geometrical dimensions of the kiln and the rotation speed. Several authors have related the time of residence to the rotation speed of rotary kilns. Let us mention those given in [20-22]. Their residence time calculations are summarized below:

[20] reported in 1951:

$$
V_{s}=\frac{k_{1} \cdot L \beta}{n \cdot D_{i} \cdot \sin }
$$

Where $k_{1}$ is a constant, $L$ the kiln length, $D_{i}$ the internal diameter of the kiln.

[21] reported in 1994:

$$
t=\frac{0.19 \cdot L}{N \cdot D_{i} \cdot S}
$$

Where $D_{i}=$ internal diameter, $L$ the length of the kiln, $N$ rotation speed, $S$ inclination slope

[22] reported in 1983:

$$
t=\frac{0.308 . L}{. D_{i}}
$$

where $D_{i}=$ internal diameter, $L$ the length of the kiln, $\omega$ rotation speed.

Formula reported by [20] requires the knowledge of the dynamic angle of repose; which is unknown in our case. The kiln slop is required in order to use the formula from [21]. Kiln is inclined $17^{\circ}$. Table 3 below give residence time calculated using formulas [21,22]. We first calibrate the rotation speed of the combustion chamber. This speed is adjustable by a crank. The rotation of the crank in the trigonometric direction increases the rotation speed. By counting ten (10) rotations clockwise and measuring the time elapsed, we obtained following speeds in Table 3.

According to the formula from [18], the residence time is found varying from 35 to 417 seconds (0.58 to 6.95) minutes. Residence time with formula from [17] appear overvalued.

Table 3. Calibration of the rotary kiln rotation speed and residence time.

\begin{tabular}{ccccccc}
\hline Rotation clockwise (turns) & 0 & 2 & 4 & 6 & 8 & 10 \\
\hline Speed (rpm) & 1.2 & 0.98 & 0.76 & 0.54 & 0.32 & 0.10 \\
RT $^{\mathrm{a}}[21]$ (s) & 72 & 88 & 114 & 161 & 271 & 867 \\
RT [22] (s) & 35 & 43 & 55 & 77 & 130 & 417 \\
RT [22] (mn) & 0.58 & 0.71 & 0.91 & 1.29 & 2.17 & 6.95 \\
\hline
\end{tabular}

${ }^{\mathrm{a}} \mathrm{RT}$ : residence time. 


\subsection{Effects of the Residence Time}

In all manipulations that follow, we will use a model waste $1 \mathrm{~kg}$ to keep constant fuel load. We will only vary the speed of the rotary kiln rotation to study its effects on pollutant releases. Table 4 below show us the variations of pollutants emissions from $1 \mathrm{~kg}$ of the model waste with residence according to formula in reference [22].

We notice that:

- $\mathrm{CO}$ and NO releases show a minimum at $55 \mathrm{~s}$ residence time. In order to reduce pollutants releases, the excess air must be introduced at appropriates points of the kiln and the residence time must well be chosen. It seems that at this residence time, the combustion is well conducted (in our experimental conditions) and thus pollutants releases are at their minimums.

- There are no traces of $\mathrm{NO}_{2}$ releases in our experiments.

- $\mathrm{SO}_{2}$ releases merely present a maximum at 55 s. Elemental formula of the used household waste model suggest that the fuel waste components used here doesn't themselves contain sulphur in appreciable proportions, the $\mathrm{SO}_{2}$ released probably originate from the primary burner (RG1) fuel. We can explain why $\mathrm{SO}_{2}$ releases are at their maximum by the fact that at the optimal residence time, the waste is well stirred and thus all the add-on combustion fuel is consumed. This indicates a more complete combustion reaction.

- $\mathrm{CO}_{2}(\%)$ releases are directly calculated by the acquisition apparatus. The minimum $(1.31 \%)$ is at $77 \mathrm{~s}$ instead of 55 s (1.48\%) for other pollutants. At 130s $\mathrm{CO}_{2}$ releases come up to $1.58 \%$. We can take the minimum as being also at 55 s with a $12 \%$ relative error.

\subsection{New Land Filling Facility Lifespan with Incineration}

We are at the end of year 2012. Let us suppose that an incinerator may be setup and is used to treat the combustible fraction of the municipal solid waste of the town of Ouagadougou as of year 2015. As official duration estimation in 2005 was 20 years, in 2015, there will only be 10 years left.

Incineration has a volume reduction rate of at least,

Table 4. Pollutants emissions with the residence time.

\begin{tabular}{cccccc}
\hline $\mathrm{RT}(\mathrm{s})$ & $\begin{array}{c}\mathrm{CO} \\
(\mathrm{mg} / \mathrm{kg})\end{array}$ & $\begin{array}{c}\mathrm{NO} \\
(\mathrm{mg} / \mathrm{kg})\end{array}$ & $\mathrm{NO}_{2}(\mathrm{mg} / \mathrm{kg})$ & $\mathrm{SO}_{2}(\mathrm{mg} / \mathrm{kg})$ & $\mathrm{CO}_{2}(\%)$ \\
\hline 35 & 546.63 & 8.98 & 0 & 4.56 & 1.62 \\
43 & 508.51 & 7.06 & 0 & 11.88 & 1.49 \\
55 & 408.42 & 6.58 & 0 & 14.23 & 1.48 \\
77 & 609.69 & 6.74 & 0 & 5.41 & 1.31 \\
130 & 414.34 & 6.92 & 0 & 12.3 & 1.58 \\
\hline
\end{tabular}

90\% therefore $\varepsilon=0.10$. From Table 2, we deduce $\beta=$ 0.1846. From Equation (9) we calculate the new duration of the land filling facility life (lifespan):

$$
d=3.07 d_{0}
$$

This result shows that the land filling facility life will at least be tripled. From 2015, we can have 31 years remaining when using incineration before land filling instead of only 10 years if only land filling is used.

There still remain various tests to be carried out in order to optimize this rotary kiln and reduce pollutants releases, but this is the first calibration procedure we have done on this laboratory scale rotary kiln before further adjustments and throughout field operation testing.

\subsection{Discussion}

Today waste incinerators are a well established municipal waste disposal method all around the world. Thought complying to environmental regulations in order to limit pollution transfer is mandatory and a prerequisite, this may be achieved by:

- Experimental testing in local condition;

- Field testing in real conditions and adaptations in order to optimize the incineration process before continuous operation;

- Continuous emissions monitoring of the incineration process and adjustment in continuous field operation;

- Lesser cost of a small or medium size rotary kiln incinerator and requirement for its setup than the cost of building a new land filling facility.

Incineration of the combustible fraction of the municipal waste of the town of Ouagadougou show that pollutants release in the atmosphere may be limited. This incineration will greatly reduce the volume of waste to be land filled. At this moment, only $6 \%$ of collected waste in the town of Ouagadougou is recycled before land filling. This should be improved. Used along with more recycling, incineration appears as a good way for reducing atmospheric pollution. The results of the combustible fraction of waste incineration mainly consist of ash, mainly consisted of inert materials. Land filling then doesn't carry serious treats for the environment as is the case with land filled of putrescible waste that undergoes biological and chemical decomposition and threatens the atmosphere and may leak in the ground.

\section{Conclusion}

As operated today, the municipal land filing centre of Ouagadougou has negatives impacts on the environment mainly due to atmospheric pollutant gases released, greenhouse gases emission, visual pollution and water contamination threat. In the lack of an environmental friendly waste disposal facility, it urges to set up one. We 
believe that waste incineration with the rotary kiln technology should be carefully considered for municipal waste disposal in Ouagadougou because this sort of kiln can be of small scale and thus enable a throughout testing on pilot scale before industrial and continuous operation.

We assessed the effects of the rotation speed of a laboratory scale rotary kiln on the operation pollutants releases during the combustion of wood together with cardboard and plastics in the proportions of the town of Ouagadougou household waste model. Using residence time calculation formula proposed in reference [22], we found that pollutants such as $\mathrm{CO}, \mathrm{NO}$ and $\mathrm{CO}_{2}$ were at the lowest values at a residence time of $55 \mathrm{~s}$. $\mathrm{SO}_{2}$ were at their highest values at the same residence time. These results although very modest, are however a first step to a better understanding of this sort of rotary kiln and further studies toward an environmental friendly waste disposal methods at Ouagadougou. It clearly appears that incinerating the combustible fraction of the municipal waste of this town will greatly extend the lifespan of its land filling facility.

\section{REFERENCES}

[1] M. Cisse, "La Propreté-Un Outil de Politique Sociale. Direction of the Cleanliness of the City of Ouagadougou,” Interview in Slate Afrique, 2012.

http://blog.slateafrique.com/terrafrica/2011/05/12/la-propr ete-un-outil-de-politique-sociale/

[2] O. Burdekin, “An Investigation into the Continuous Monitoring of Landfill Gas and the Commercial Viability of the Intelysis landfill Gas Monitor," Manchester University, Manchester, 2003.

[3] J. Brosseau, "Trace Gas Compound Emissions from Municipal Landfill Sanitary Sites," Atmospheric-Environment, Vol. 28, No. 2, 1994, pp. 285-293. doi:10.1016/1352-2310(94)90103-1

[4] T. H. Christensen, R. Cossu and R. Stegmann, "Landfilling of Waste: Biogas,” 1999.

[5] Environmental Protection Agency, “Methane,” 2012. http://epa.gov/climatechange/ghgemissions/gases/ch4.htm l

[6] ADEME, "La Gestion des Déchets en France, Evolutions Essentielles Depuis 1992,” Angers, 2001.

[7] FME (Federal Ministry for Environment, Nature Conservation and Nuclear Safety of Germany), "Waste Incineration-A Potential Danger? Bidding Farewell to Dioxin Spouting.” 2005.

http://www.bmu.de/files/english/pdf/application/pdf/muel lverbrennung_dioxin_en.pdf

[8] Law \& Your Environment, "Landfill Waste Disposal," 2012. http://www.environmentlaw.org.uk/rte.asp?id=243

[9] M. D. Heydenrych, "Modelling of Rotary Kilns," Thesis
University of Twente, Enschede, 2001.

[10] Penta Engineering Corporation, "Report on NOx Formation and Variability in Portland Cement Kilns SystemsPotential Control Techniques and Their Feasibility and Cost Effectiveness,” PCA R\&D Serial No. 2227, Skokie, 1999.

[11] Young, "NOx Formation in Rotary Kilns Producing Cement Clinker Applicable NOx Control Techniques and Cost Effectiveness of These Control Techniques,” 2002.

[12] RIELLO S.p.A., "Technical Handbook of the RG1 Burner,” Via degli Alpini, 1-37045 Legnago (VR) Italia, 2001.

http://www.rielloburners.co.uk/lumo/upload_documents/r iello_gulliverrg1363t1manual.pdf

[13] M. Proust, “Caractérisation des Déchets Ménagers de la Ville de Ouagadougou,” Mémoire de Master, Laboratoire de Physique et de Chimie de l'Environnement, Université de Ouagadougou, Ouagadougou, 2001.

[14] J. Tezanou, "Evaluation Environnemental et Technique de la Gestion des Déchets Ménagers de Ouagadougou: Schémas de Gestion et Expérimentation de Traitement Thermique,” Ph D Thesis, University of Poitiers, Poitiers, 2003.

[15] P. Robert, "De la Forêt aux Chaufferies à Bois à Alimentation Automatique,” Institut Pour le Développement Forestier, Éditeur, 1985.

[16] R. Dumon and M. Gelus, "Valorisation Chimique du Bois. Chap III: Préparation Chimique du Bois de Feu,” Edition Masson, Koudougou, 1982, pp. 8, 9, 11.

[17] T. Rogaume, "Caractérisation Expérimentale et Modélisation de l'Emission de Polluants lors de l'Incinération des Déchets Ménagers,” PhD Thesis, University of Poitiers, Poitiers, 2001.

[18] J. F. Nzihou, “Modélisation d'un Four Thermique Rotatif: Influence des Paramètres de Fonctionnement sur la Performance Thermique et les Emissions Polluantes en Incinérateur,” $\mathrm{PhD}$ Thesis, University of Ouagadougou, Ouagadougou, 2005.

[19] S. Kerdsuwan, “Contribution à l’Etude de l’Incinération des Déchets Urbains: Expérimentation en Four Thermique Rotatif, Optimisation et Modélisation Thermique en Fonctionnement," PhD Thesis of the University of Poitiers, Poitiers, 1994.

[20] W. C. Seaman, "Passage of Solid through Rotary Kiln," Chemical Engineering Progress, Vol. 47, No. 10, 1951, pp. 508-514.

[21] J. Perron and R. T. Bui, "Rotary Cylinders: Transverse Bed Motion Prediction by Rheological Analysis," The Canadian Journal of Chemical Engineering, Vol. 70, No. 2, 1992, pp. 223-231. doi:10.1002/cjce.5450700203

[22] P. S. Kochar, "Simulation of Rotary Lime Kiln: Impact of Alternative Fuels and Dams," PhD Thesis, Department of Chemical Engineering, University of Idaho, Moscow, 1983. 